\title{
Comparison between 1-D and grey-box models of a SOFC
}

\author{
Ramin Moradi ${ }^{1, *}$, Andrea Di Carlo ${ }^{2}$, Federico Testa ${ }^{1}$, Luca Del Zotto ${ }^{3}$,Enrico Bocci ${ }^{4}$, and Emanuele Habib ${ }^{1}$ \\ ${ }^{1}$ DIAEE, Sapienza University of Rome, Rome, Italy \\ ${ }^{2}$ Department of Chemistry, Chemical Engineering and Materials, University of Aquila, L'Aquila, Italy \\ ${ }^{3}$ Universita Telematica e-Campus, Novedrate, CO, Italy \\ ${ }^{4}$ Marconi University, Rome, Italy
}

\begin{abstract}
Solid Oxide Fuel Cells (SOFCs) have shown unique performance in terms of greater electrical efficiency and thermochemical integrity with the power systems compared to gas turbines and internal combustion engines. Nonetheless, simple and reliable models still must be defined. In this paper, a comparison between a grey-box model and a 1-D model of a SOFC is performed to understand the impact of the heat transfer inside the cell on the internal temperature distribution of the solid electrolyte. Hence, a significant internal temperature peak of the solid electrolyte is observed for a known difference between anode and cathode inlet temperatures. Indeed, it highlights the difference between the 1-D model and the grey-box model regarding the thermal conditioning of the SOFC. Therefore, the results of this study can be used to investigate the reliability of the thermal results of box models in system-level simulations.
\end{abstract}

\section{Nomenclature}

\begin{tabular}{|c|c|c|}
\hline$\Delta \mathrm{H}_{\text {reac }}$ & Enthalpy of reaction & $\mathrm{J} / \mathrm{mol}$ \\
\hline$\varepsilon$ & Electrical efficiency of the fuel cell & {$[-]$} \\
\hline$\eta_{\text {Act,a }}$ & Anode activation polarization & $\mathrm{V}$ \\
\hline$\eta_{\text {Act,c }}$ & Cathode activation polarization & $\mathrm{V}$ \\
\hline$\eta_{\text {Conc,a }}$ & Anode concentration polarization & $\mathrm{V}$ \\
\hline 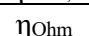 & Ohmic polarization & $\mathrm{V}$ \\
\hline$\eta_{\text {Tot }}$ & Total polarization & $\mathrm{V}$ \\
\hline $\mathrm{F}$ & Faraday constant & $\mathrm{C} / \mathrm{mol}$ \\
\hline $\mathrm{J}$ & Current density & $\mathrm{A} / \mathrm{m}^{2}$ \\
\hline $\mathrm{n}_{\mathrm{e}}$ & Electrons transferred per reaction & - \\
\hline Sel & $\begin{array}{l}\text { Areic mole flow of electrons through } \\
\text { the electrolyte }\end{array}$ & $\mathrm{mol} / \mathrm{m}^{2} . \mathrm{s}$ \\
\hline $\mathrm{V}$ & Output fuel cell voltage & $\mathrm{V}$ \\
\hline \multicolumn{3}{|c|}{ Subscripts } \\
\hline & Anods & Anode \\
\hline \multirow{2}{*}{\multicolumn{2}{|c|}{$\frac{\mathrm{e}}{\mathrm{c}}$}} & Electrolyte \\
\hline & & \\
\hline
\end{tabular}

\section{Introduction}

Highly efficient, clean and sustainable technologies to produce electricity from fossil fuels and renewable sources have been studied in many academic and industrial projects at national and international scales. Fuel Cells (FCs) are electrochemical devices that directly convert the chemical energy of the fuel into the electricity.

The process is highly efficient and clean. FCs have shown unique performance compared to conventional power systems such as steam turbine (ST) cycles
(Rankine), gas turbine (GT) cycles (Brayton), and internal combustion engine (ICE) cycles (Diesel or Otto), which their maximum efficiency are inherently limited to Carnot cycle principle. However, FCs operate with limited fuel types and they require a higher level of cleanness of the fuel compared to the conventional systems [1].

FCs can be divided into two general categories of lowtemperature and high-temperature ones. While lowtemperature FCs operate mainly with $\mathrm{H}_{2}$ as the fuel, hightemperature FCs are more flexible to exploit $\mathrm{H}_{2}, \mathrm{CH}_{4}, \mathrm{CO}$ and their mixtures. Solid-Oxide FCs (SOFCs) operate in high-temperatures and reach to plant electrical efficiency of about 50\% [1]. Moreover, the higher conversion efficiency and power density of these systems can be highlighted further in small-scale power plants [2]. Because of the high-temperature performance of SOFC units, they can be integrated with bottom cycles such as GTs to increase the overall efficiency of the combined plant. The rejected heat from such an integrated system can be exploited further in a CHP unit to meet users' thermal demands. Considering the operating temperature of SOFCs $\left(700-800{ }^{\circ} \mathrm{C}\right)$, they can be integrated with biomass gasification units if the produced synthesis gas is purified to the required level of the SOFC [3].

Temperature distribution in the SOFC structure is an important factor in the design of the cell and the power system. Hence, levelling of temperature distribution is required especially for planar SOFCs to avoid cell deterioration during its operation. Indeed, the high local temperature inside the cell may lead to chemical reactions

\footnotetext{
* Corresponding author: ramin.moradi@uniromal.it
} 
between the electrode and electrolyte materials and thermal stresses to the cell structure [4].

In this paper, a comparison between a 1-D model and a grey-box model of a SOFC is performed to understand the impact of the heat transfer inside the cell on the internal temperature distribution of the solid electrolyte. Hence, a significant internal temperature peak of the solid electrolyte is observed for a known difference between anode and cathode inlet temperatures. Indeed, it highlights the difference between the 1-D model and the grey-box model regarding the thermal conditioning of the SOFC. Therefore, the results of this study can be used to investigate the reliability of the thermal results of box models in system-level simulations.

\section{Modelling of the SOFC}

In this study, a SOFC is simulated using a grey-box model in ASPEN Plus ${ }^{\circledR}$, and a 1-D model developed in MATLAB $^{\odot}$. To make the comparison possible, the geometry of the SOFC and inputs of both models are considered the same as summarized in Table 1.

Table 1. Input parameters to the models

\begin{tabular}{|c|c|c|}
\hline \multicolumn{3}{|c|}{ Anode inlet gas } \\
\hline \multicolumn{2}{|c|}{$\mathrm{H}_{2}[\%$ mole] } & 97 \\
\hline \multicolumn{2}{|c|}{$\mathrm{H}_{2} \mathrm{O}[\%$ mole] } & 3 \\
\hline \multicolumn{2}{|c|}{$P_{\text {in }}[$ bar $]$} & 1 \\
\hline \multicolumn{2}{|c|}{$T_{\text {in }}\left[{ }^{\circ} \mathrm{C}\right]$} & 800 \\
\hline \multicolumn{3}{|c|}{ Cathode inlet gas } \\
\hline \multicolumn{2}{|c|}{$\mathrm{O}_{2}[\%$ mole] } & 21 \\
\hline \multicolumn{2}{|c|}{$\mathrm{N}_{2}[\%$ mole] } & 79 \\
\hline \multicolumn{2}{|c|}{$P_{\text {in }}[$ bar] } & 1 \\
\hline \multicolumn{2}{|c|}{$\mathbf{T}_{\text {in }}\left[{ }^{\circ} \mathbf{C}\right]$} & 700 \\
\hline \multicolumn{2}{|c|}{ UF (Fuel Utilization factor) } & 0.80 \\
\hline \multicolumn{2}{|c|}{$\mathrm{U}_{\mathrm{O}}\left(\mathrm{O}_{2}\right.$ Utilization factor $)$} & 0.12 \\
\hline \multicolumn{3}{|c|}{ Geometrical parameters (for 1-D model) } \\
\hline $\begin{array}{c}\delta \text { a }[\mu \mathrm{m}] \\
\text { (anode thickness) }\end{array}$ & $\begin{array}{c}\delta_{\mathrm{e}}[\mu \mathrm{m}] \\
\text { (electrolyte } \\
\text { thickness) }\end{array}$ & $\begin{array}{c}\delta_{\mathrm{c}}[\mu \mathrm{m}] \\
\text { (cathode } \\
\text { thickness) }\end{array}$ \\
\hline 750 & 50 & 50 \\
\hline \multicolumn{2}{|c|}{ L [m] (cell length) } & 0.4 \\
\hline \multicolumn{2}{|c|}{$\mathrm{W}_{\mathbf{y}}[\mathrm{m}]$ (cell width) } & 0.1 \\
\hline
\end{tabular}

\subsection{1-D model of the SOFC}

The developed model solves the heat and mass-species differential equations in the SOFC, and the electrochemical conversion of the chemical energy of the fuel $\left(\mathrm{H}_{2}\right)$ using the $5^{\text {th }}$-order boundary value solver function in MATLAB $^{\odot}$. The model considers the evolution of the composition of the gas mixtures in anode and cathode streams along the length of the SOFC, and the heat transfer through the solid electrolyte in the direction of the thickness of the SOFC. The following assumptions are considered in the model:

- $\quad$ Steady-state conditions.

- Identical convective heat transfer coefficients from the solid electrolyte to both anode and cathode streams.
- Constant specific heat of the gas mixtures is considered at the inlet temperature of the anode and cathode streams.

- $\quad$ The SOFC is an adiabatic system.

- Heat transfer due to mass transfer between electrolyte and anode and cathode streams was neglected.

The mathematical model of the SOFC is consisted of a series of equations to calculate the produced voltage by the cell and the three main losses namely activation, ohmic and concentration polarization losses. The mathematical model of the SOFC used in the 1-D model is not presented fully in this paper for conciseness, and it is described in details in [5].

A fraction of the generated heat due to the reaction of $\mathrm{H}_{2}$ inside the solid electrolyte is converted to the electricity and the rest is transferred to the counter-current flow streams in the cathode and anode. Equation (1) represents the energy balance in the solid electrolyte neglecting the conduction heat transfer term in the direction of the thickness of the electrolyte due to its very low thickness.

$$
\begin{gathered}
\delta_{\text {tot }} k_{e} \frac{\partial^{2} T_{e}}{\partial x^{2}}-h_{a}\left(T_{e}-T_{a}\right)-h_{c}\left(T_{e}-T_{c}\right) \\
+s_{e l} \Delta H_{\text {reac }}-V \cdot J=0
\end{gathered}
$$

The second and third terms in Eq (1) represent the convective heat transfer from the solid electrolyte to the anode and cathode streams. The last two terms represent the total enthalpy of reaction and the electrical power output respectively. Therefore, the sum of these two terms is equal to the generated heat in the solid electrolyte. The parameter $\mathrm{s}_{\mathrm{el}}$ is the areic molar flow of electrons through the electrolyte.

$$
s_{e l}=\frac{J}{n_{e} F}
$$

where $\mathrm{F}$ is the Faraday constant, $\mathrm{J}$ is the current density and $n_{e}$ is the number of transferred electrons per reaction.

The energy balance in the anode and cathode streams are represented in Eq (3) and (4) respectively:

$$
\begin{gathered}
\dot{N}_{a} \overline{\mathbf{c}}_{p a} \frac{\partial T_{a}}{\partial x}=h_{a} W_{y}\left(T_{e}-T_{a}\right) \\
\dot{N}_{c} \overline{\mathbf{c}}_{p c} \frac{\partial T_{c}}{\partial x}=-h_{c} W_{y}\left(T_{e}-T_{c}\right)
\end{gathered}
$$

where $\mathrm{h}$ is the convective heat transfer coefficient, $\mathrm{W}_{\mathrm{y}}$ is the cell width, and $\mathrm{C}_{\mathrm{p}}$ is the specific heat of the gas mixture. The negative sign in Eq (4) is to consider the counter flow streams in the solution of the system of the governing equations.

The mass-species balance in each stream is considered using Eq (5) for each species: 


$$
\begin{aligned}
\frac{\partial \dot{N}_{l a}}{\partial x} & =v_{i, a} s_{e l} W_{y} \\
\frac{\partial \dot{N}_{l c}}{\partial x} & =-v_{i, c} s_{e l} W_{y}
\end{aligned}
$$

where $\dot{\mathrm{N}}_{\mathrm{i}}$ is the mole flow rate of each component (at anode-a and cathode-c) of the gas mixture and $v$ is the stoichiometric coefficient of the components in the relevant reaction, positive for the product and negative for reagents.

The inlet mole flow rates of the reactants are calculated as the following:

$$
\begin{aligned}
& \dot{N}_{H_{2}, \text { in }}=\frac{\mathrm{J} \cdot L \cdot W_{y}}{2 \mathrm{~F} \cdot \mathrm{U}_{\mathrm{F}}} \\
& \dot{N}_{O_{2}, \text { in }}=\frac{\mathrm{J} \cdot L \cdot W_{y}}{4 \mathrm{~F} \cdot \mathrm{U}_{\mathrm{O}}}
\end{aligned}
$$

where $U_{F}$ and $U_{O}$ are inputs to the model (Table 1), and multipliers of $\mathrm{F}$ indicate number of exchanged electrons per molecule of the reactant.

The SOFC is divided into differential-size cells (100 nodes) along its length (x-direction) and an iterative solver is performed to solve a system of equations ( 9 equations in total) described above at the same time. The convergence of the solution is achieved when the residual of the electrolyte temperature in nodes is less than the specified tolerance.

\subsubsection{Model validation}

The results of the 1-D model developed in this study are compared with the results presented by Chan et al. [5] in the range of power density between 0 and $14000 \mathrm{~A} / \mathrm{m}^{2}$ as reported in Table 2. It is evident that the results of output voltage $(V)$ and the total over-voltage $\left(\eta_{\text {tot }}\right)$ from the 1-D model in this work are in agreement with the results presented in [5] although the geometry of the cell was not presented in their work. Furthermore, the data presented in Table 2 are plotted in Fig. 1 for a better understanding of the trend of the results of both works.

Table 2. Comparison between the 1-D model and [5]

\begin{tabular}{|c|c|c|c|}
\hline $\mathbf{J}\left[\mathbf{A} / \mathbf{m}^{2}\right]$ & $\begin{array}{c}\text { V [V] (1-D } \\
\text { model) }\end{array}$ & $\begin{array}{c}\mathbf{V}[\mathbf{V}] \\
([\mathbf{5}])\end{array}$ & $\begin{array}{c}\text { Relative Error } \\
{[\mathbf{\%}]}\end{array}$ \\
\hline 0 & 1.09 & 1.1 & $1 \%$ \\
\hline 2000 & 0.88 & 0.91 & $3 \%$ \\
\hline 4000 & 0.74 & 0.77 & $4 \%$ \\
\hline 6000 & 0.59 & 0.65 & $9 \%$ \\
\hline 8000 & 0.46 & 0.55 & $16 \%$ \\
\hline 10000 & 0.33 & 0.45 & $27 \%$ \\
\hline 12000 & 0.20 & 0.37 & $46 \%$ \\
\hline 14000 & 0.06 & 0.29 & $79 \%$ \\
\hline & & & Relative Error \\
{$\left[\mathbf{J}\left[\mathbf{A} / \mathbf{m}^{2}\right]\right.$} & $\eta_{\text {tot }}(\mathbf{1 - D}$ model) & $\boldsymbol{\eta}_{\text {tot }}([\mathbf{5}])$ & \\
\hline
\end{tabular}

\begin{tabular}{|c|c|c|c|}
\hline 0 & 0 & 0 & $0 \%$ \\
\hline 2000 & 0.19 & 0.18 & $5 \%$ \\
\hline 4000 & 0.34 & 0.33 & $6 \%$ \\
\hline 6000 & 0.49 & 0.46 & $7 \%$ \\
\hline 8000 & 0.62 & 0.57 & $9 \%$ \\
\hline 10000 & 0.75 & 0.66 & $14 \%$ \\
\hline 12000 & 0.88 & 0.75 & $17 \%$ \\
\hline 14000 & 1.03 & 0.82 & $26 \%$ \\
\hline
\end{tabular}

The discrepancy between the two models increases in higher values of current density. In particular, the 1-D model in this work results in lower output voltage compared to the reference model from $1 \%$ and $79 \%$ at maximum $\mathrm{J}$.

This discrepancy is due to the approach adopted in this work compared to that of [5]. In [5] no energy equation is solved, and the temperature is set constant and equal to $1073 \mathrm{~K}$. In this study instead the energy equation is solved, and the distribution of temperature is obtained as a result. The temperature distribution as also the average temperature of the cell depends on the operating conditions adopted. An increase in the current density brings to an increase of the cell temperature. This increase leads to an increase of polarization losses as shown in the relationships of Chan et al. [5] and adopted also in this work.

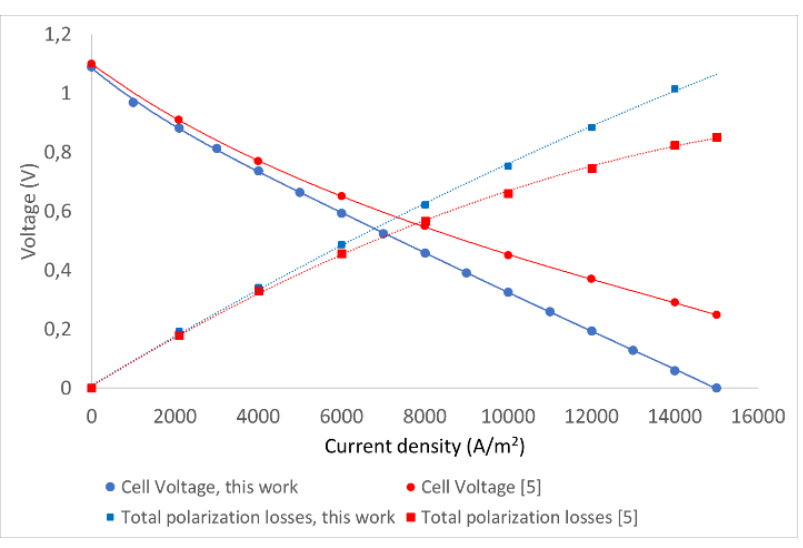

Fig. 1. Comparison between the results of the 1-D model in this work and in [5]

This evidence underlines the importance to evaluate the temperature distribution inside the cell and therefore the importance to develop models able to compute this distribution and to be used for finding the appropriate operating conditions to control it.

\subsection{Gray-box model of the SOFC}

The grey-box model is performed using a series of blocks in Aspen Plus ${ }^{\circledR}$ to simulate the combustion reaction of $\mathrm{H}_{2}$ in the solid electrolyte and the thermal balance between the cathode and anode of the SOFC. The flowsheet of the SOFC model is presented in Fig. 2. Fuel and air are entered two separator blocks named ANODE and CATHODE respectively. The $\mathrm{U}_{\mathrm{F}}$ and $\mathrm{U}_{\mathrm{O}}$ are inputs in these blocks to determine the flow rate of $\mathrm{H}_{2}$ and $\mathrm{O}_{2}$ that 
participate in the stoichiometric combustion reaction in the ELECTROL block that simulates the reactions in the solid electrolyte of the SOFC. This block is assumed isothermal to find out the total heat of reaction of $\mathrm{H}_{2}$ that is calculated from the heat duty of the block. A part of the heat duty is consumed to produce electricity in the SOFC, and the rest is transferred to anode and cathode streams (assuming the SOFC is fully isolated). Therefore, the total heat that is divided between the streams is calculated using Eq. (7):

$$
Q=\text { Duty } \times(1-\varepsilon)
$$

where $\varepsilon$ is the electrical efficiency of the SOFC, and it is about 0.3 at the current density of $10000 \mathrm{~A} / \mathrm{m}^{2}$ and it is assumed fixed in the model. The produced products of the reaction are mixed with the separated stream of the fuel. Then, both streams pass through heaters with equal thermal loads ( $35 \%$ of the calculated heat duty) since the convective heat transfer coefficients are assumed the same in anode and cathode sides in the 1-D model.

Finally, they pass through a heat exchanger block to simulate the heat transfer between anode and cathode streams through the solid electrolyte. To simulate the heat transfer phenomena, the effective area of the cell (Length $\times$ Width) and the overall heat transfer coefficient (U) are entered to the heat exchanger block as inputs. Hence, the model becomes a grey-box one. Furthermore, it is evident from the configuration of the model that the impact of the diffusion of the cathode stream to the anode stream on the heat transfer (and final temperature of the streams accordingly) is neglected in this model.

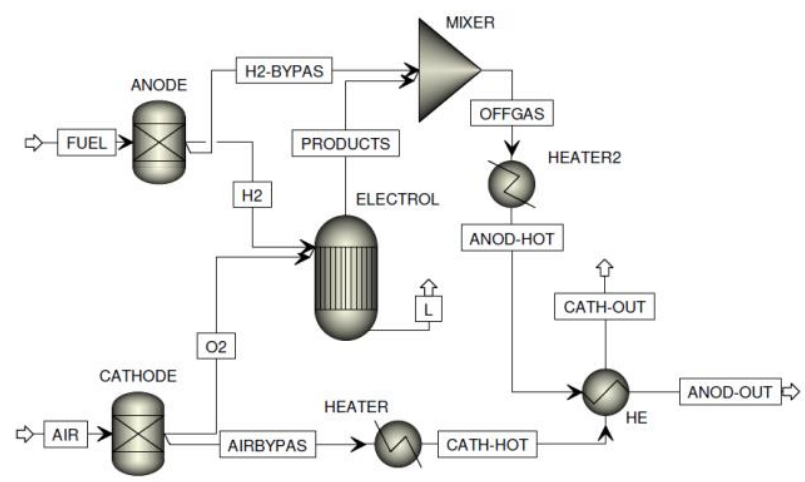

Fig. 2. Flowsheet of the model of SOFC in Aspen Plus ${ }^{\circledR}$

The super-position of the combustion reaction of $\mathrm{H}_{2}$ and the heat transfer is used in the grey-box model instead of considering their instantaneous interaction as in the 1$\mathrm{D}$ model. Because of the super-positioning, the temperature of the anode stream at the inlet of the heat exchanger is unphysically high. While in the 1-D model (and in reality) both streams exchange heat during the combustion of $\mathrm{H}_{2}$ resulting in a limited temperature difference between the two streams. Therefore, although both models are identical from the first law of thermodynamics point of view, their results are different if an exergy analysis is carried out.

The super-positioning is a valid assumption for the grey-box modelling in this study considering that the irreversibility due to high-temperature heat transfer is not concerned.

\section{Results and discussion}

The results of the 1-D and the grey-box models of the single-cell SOFC are described considering the same inputs reported in Table 1. Figure 3 shows the evolution of the absolute partial pressure of each component of the anode and cathode gas mixtures along the normalized length of the cell ( 0 indicates the inlet of the anode stream). The rate of variations of $\mathrm{H}_{2}$ and $\mathrm{H}_{2} \mathrm{O}$ contents in the anode gas is significantly higher than the components $\left(\mathrm{O}_{2}\right.$ and $\left.\mathrm{N}_{2}\right)$ of the cathode stream due to the considerably less flow rate of the anode stream compared to the cathode stream.

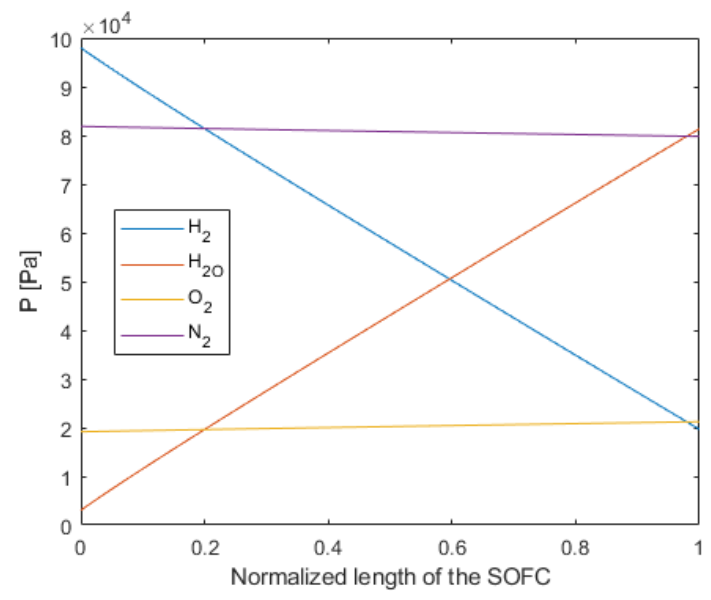

Fig. 3. The partial pressure 5 of components of the gas mixtures inside the SOFC ( 0 indicates the anode inlet)

The theoretical voltage of the cell $\left(\mathrm{E}_{0}\right)$, the total overvoltage $\left(\eta_{\text {tot }}\right)$, and the output voltage $(\mathrm{V})$ are shown in Figure 4 . The produced voltage is almost constant in the cell with a maximum close to the anode inlet showing the higher reaction rate of $\mathrm{H}_{2}$ in this zone.

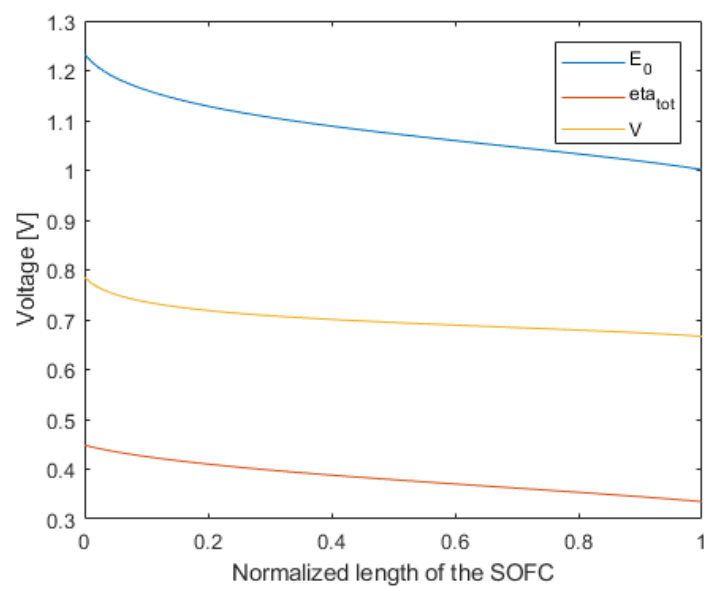

Fig. 4. The theoretical voltage $\left(\mathrm{E}_{0}\right)$, the total over-voltage losses $\left(\eta_{\text {tot }}\right)$, and the output voltage $(\mathrm{V})$ inside the SOFC (0 indicates the anode inlet) 
The three main losses inside the SOFC that are included in the model are shown separately in Fig. 5. These losses are activation, ohmic and concentration losses that reduce the produced power of the SOFC. The details of the loss models of the SOFC are described in [5].

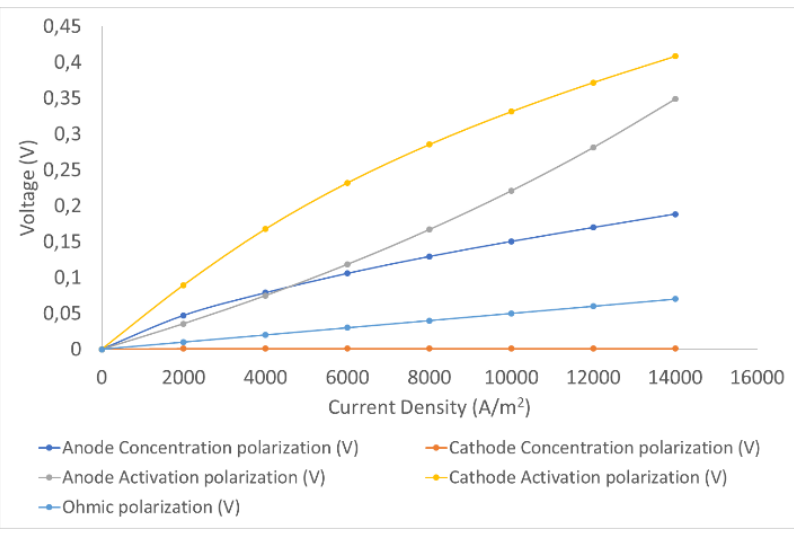

Fig. 5. The main losses in the anode and cathode streams via current density

The produced power and the electrical efficiency of the SOFC are presented in Fig. 6 along with the average produced voltage. The electrical efficiency is calculated as $\mathrm{Eq}(8)$ :

$$
\varepsilon=\frac{V \cdot J \cdot L \cdot W_{y}}{\dot{N}_{H 2, \text { react }} \cdot \Delta H_{\text {reac }}}
$$

where $\dot{\mathrm{N}}_{\mathrm{H} 2 \text {,react }}$ is the reacted hydrogen during the process.

Although the electrical efficiency of the cell decreases monotonously as the current density increases, the produced power of the cell reaches a peak at a current density of about $8000\left[\mathrm{~A} / \mathrm{m}^{2}\right]$. Therefore, the current density in the vicinity of this point can be chosen as the operational point of the SOFC, where the produced power is at its peak and the electrical efficiency is penalized to some extents.

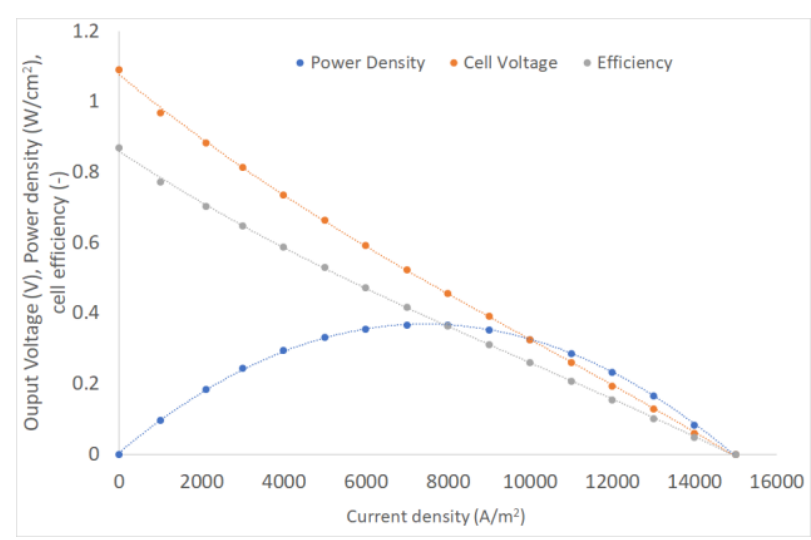

Fig. 6. The output voltage, power density and electrical efficiency via the current density

The temperature distribution inside the SOFC is shown in Fig. 7. The temperature profile of the anode and the solid electrolyte reach a peak located close to the inlet of the anode showing the higher rate of the combustion reaction inside the solid electrolyte, where a high concentration of $\mathrm{H}_{2}$ results in the peak of rate the generated thermal energy in the solid electrolyte.

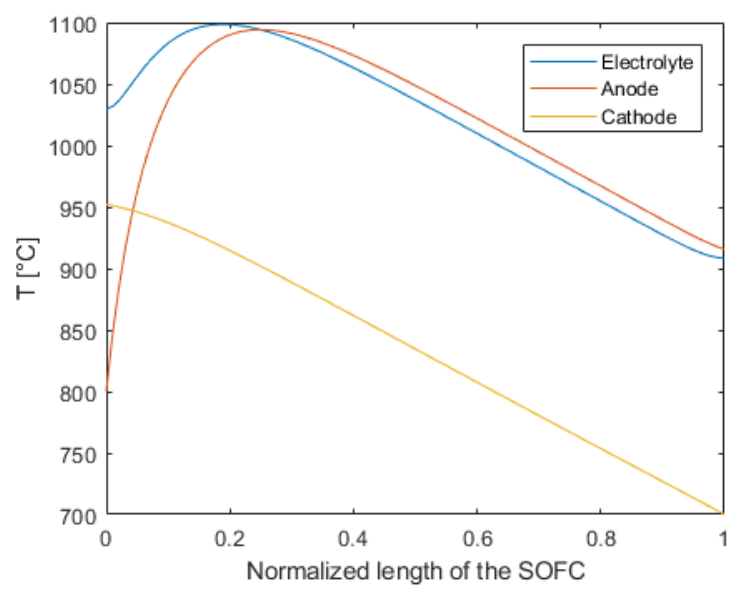

Fig. 7. Temperature distribution in the anode, electrolyte and cathode streams ( 0 indicates the anode inlet)

It is evident from Fig. 7 that the peak of the temperature in the solid electrolyte is very close to the peak of the anode temperature. In addition, the difference between the inlet and peak temperatures in the solid electrolyte is significantly higher than the difference between the temperatures of its ends. Therefore, if a box model gives the temperature results as a 1-D model, the internal temperature peak would be very different, and it cannot be neglected during the design of an energy system.

In other words, even if a box model shows the desired performance of the SOFC in the system-level simulation, it should be noted that the SOFC structure may prone to the risk of thermal stresses due to the internal temperature pinch.

Thermal results of the grey-box model are presented in Fig. 8. The outlet temperature of the cathode stream is slightly over-predicted compared to the 1-D model, while the outlet temperature of the anode stream is underpredicted and its difference with results of 1-D model is larger than the cathode outlet temperature. Nevertheless, the grey-box model represents acceptable accuracy on modelling the overall thermal performance of the SOFC, which is useful for a preliminary system-level simulation and energy analysis.

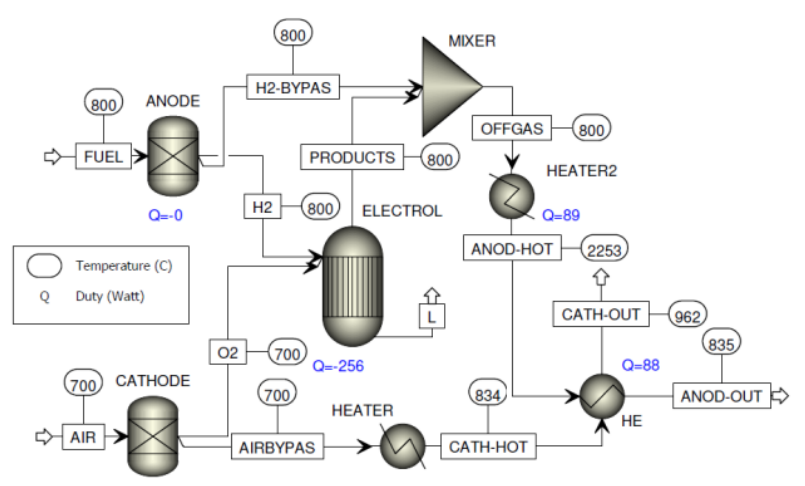

Fig. 8. Temperature distribution in the anode, electrolyte and cathode streams ( 0 indicates the anode inlet) 
It is evident that due to the super-positioning of the reaction of $\mathrm{H}_{2}$ and heat transfer between the streams, the temperature of anode off-gas that enters the heat exchanger is unphysically high. Therefore, the thermal results of the grey-box model would be improved if the reactor and heat transfer blocks are repeated in series in order to consider more steps of heat generation in the solid electrolyte and heat transfer between anode and cathode streams. The impact of this approach on the energy and exergy analysis of the SOFC will be studied in future works.

\section{Conclusions}

A single-cell SOFC is simulated in this paper using a 1-D and a grey-box model. Results of the 1-D model revealed that the internal temperature peak in the solid electrolyte is significantly higher than the temperature results of the grey-box model. Therefore, a simplified grey or blackbox model that is useful for preliminary system-level simulations of SOFCs integrated to power systems should be used paying attention to the internal temperature distribution of the SOFC that is not considered in box models. Hence, a SOFC unit that shows good thermal integrity with the power system may prone to significant material deterioration and thermal stresses if operated in the real system due to its internal temperature distribution.

\section{References}

1. E. Bocci, A. Di Carlo, S. J. McPhail, K. Gallucci, P. U. Foscolo, M. Moneti, M. Villarini, M. Carlini, Int. J. Hydrogen Energy, Biomass to Fuel Cells State of the Art: A Review of the Most Innovative Technology Solutions, 39, 21876-21895 (2014)

2. A. Di Carlo, D. Borello, E. Bocci, Int. J. Hydrogen Energy, Process Simulation of a Hybrid SOFC/MGT and Enriched Air/Steam Fluidized Bed Gasifier Power Plant, 38, 5857-5874 (2013)

3. Z. U. Din, Z. A. Zainal, Renew. Sustain. Energy Rev., Biomass Integrated Gasification-SOFC Systems: Technology Overview, 53, 1356-1376 (2016)

4. S. Nagata, A. Momma, T. Kato, Y. Kasuga, J. Power Sources, Numerical Analysis of Output Characteristics of Tubular SOFC with Internal Reformer, 101(1), 60-71 (2001)

5. S. H. Chan, K. A. Khor, Z. T. Xia, J. Power Sources, A Complete Polarization Model of a Solid Oxide Fuel Cell and Its Sensitivity to the Change of Cell Component Thickness, 93, 130-140 (2001) 